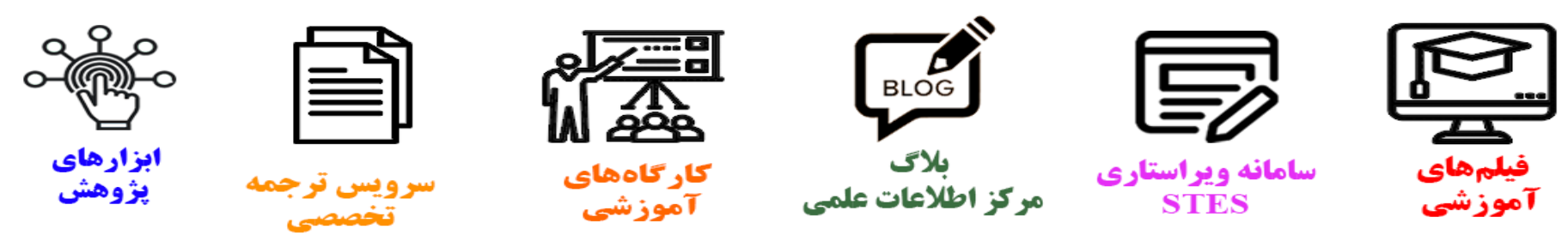

\title{
(c)
}

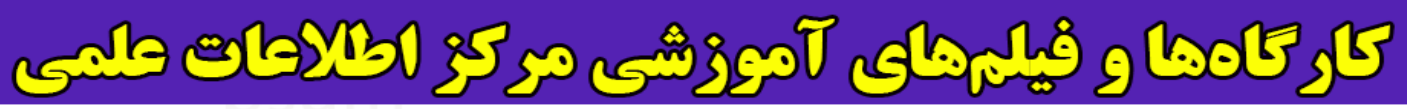
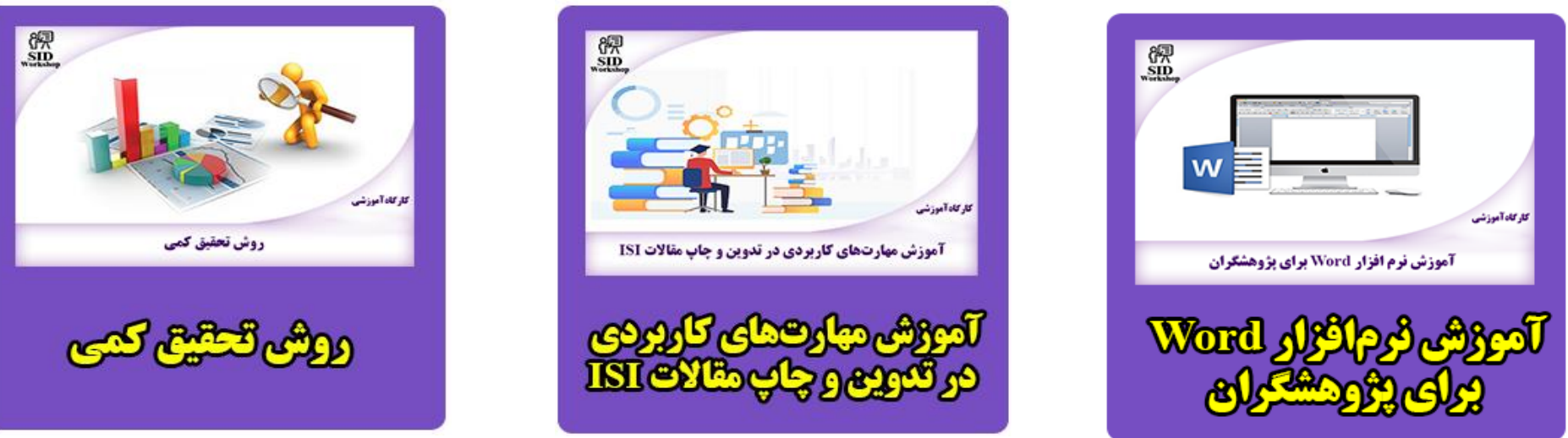


\title{
International Journal of Engineering
}

Journal Hom e page: ww w. i je.ir

\section{Review Heat Exchanger: Research Development of Self-rotating Inserts in Heat Exchanger Tubes}

\author{
Z. Cancan, L. Yafei, W. Li, X. Ke, W. Jinxing* \\ School of Chemical and Energy Engineering, Zheng Zhou University,Zheng Zhou ,China
}

\section{$P A P E R \quad I N F O$}

Paper history:

Received 18 January 2014

Received in revised form 17 May 2014

Accepted26 June 2014

\section{Keywords:}

TubeInserts

Self-rotating,

Heat Transfer Enhancement

Anti-scaling and Descaling

\section{$A B S T R$ A $C$ C}

Heat exchangers are widely used in power engineering and industrial applications. Many techniques such as coiled tube, surface tension devices, rough surfaces and extended surfaces have been investigated to enhancethermal performance and minimize the cost and size of the heat exchanger equipment. One of the most important techniques is tube insert, In general,tube inserts can be classified into two broad categories: stationary inserts and self-rotating inserts.Compared with stationary inserts, the self-rotating inserts can rotate in the tube by fluid and the comprehensive performance of selfrotating inserts is improved significantly. This paper mainly focuses on reviewing the large number of experimental and numerical works taken by researchers on self-rotating inserts such as twisted tapes,miniature hydraulic turbine,turbine-type swirl generators, etc. To improve the thermal efficiency of heat exchanger and serviceable to designers implemention of passive enhancement techniques in heat exchanger are required. The authors found that self-rotating inserts can streng then the heat transfer efficiency, meanwhile achieve on-line automatic anti-scaling and descaling effect. When the fluid velocity is more than $0.2 \mathrm{~m} / \mathrm{s}$, most of self-rotating inserts can be applied.The heat transfer performance and frictional loss have been discussed to get the optimal configuration of self-rotating inserts. The convective heat transfer correlations have also been discussed. Determining how to find the optimal self-rotating insert is the main objective of this paper..

doi: 10.5829/idosi.ije.2014.27.10a.03

\section{INTRODUCTION}

Heat exchanger equipments are widely used in the chemical industry, power engineering, refrigeration and air conditioning, etc. Improving the efficiency of heat exchanger equipment not only can conserve energy and protect the environment, it also can save investment and operating costs as well [1-5].

As one of the most simply improved heat transfer technology heat transfer augmentation techniques, tube inserts technology has been widely used in heat exchangers. Tube inserts technology can be divided into two categories. The first is the active technique and the other is the passive one. For the active technique, external force such as jet impingement, stirring of the fluid, fluid and surface vibration, and electric field are

*Corresponding Author's Email: kievenlee@163.com (WU Jinxing) required. Equally, the passive technique requires special surface geometries such as extended surface, displaced inserts, swirl flow inserts, and surface roughening. Many researchers have studied and have tried to develop the new type of inserts for increasing the thermal performance and reducing the pressure drop inside the common plain tube to be as low as possible [6-11].

Passive tube inserts can be divided into stationary and self-rotating inserts. Stationary inserts such as static mixer conical ring and so on, have the relatively fixed position in the pipe. Self-rotating inserts such as twisted tapes, miniature hydraulic turbine, and the like are defined so because they can rotate automatically while the fluid in the tube is flowing [12-14].

Stationary inserts include twisted tape, ribs, conical nozzle, which was found by Liu and Sakr [15] that significantly improved the heat transfer process; also, twisted tape inserts are widely investigated; which are 
used to enhance the heat transfer efficiency of heat exchangers.

Different techniques have their work-specific applications. Twisted tape inserts have better performance in laminar flow than turbulent flow. However, some other passive techniques such as ribs, conical nozzle, and conical ring, etc. are usually more efficient in the turbulent flow than in the laminar flow.

Self-rotating inserts can strengthen the heat transfer efficiency, meanwhile achieve on-line automatic antiscaling and descaling effect. This is because selfrotating inserts change the direction of fluid flow, form a rotational flow, get the bulk flow and fluid at the tube surface mixed and disrupt the development of boundary layer. A variety of developed self-rotating inserts are popularly researched by many scholars both at home and abroad and widely used for heat exchangers because of the simple manufacturing process, easy installation and operation. Different self-rotating inserts have different shapes and principles of heat transfer enhancement. This paper reviews the experimental and numerical work of employing self-rotating inserts and display their findings.

\section{THE CONFIGURATION DEVELOPMENT OF SELF- ROTATING INSERTS}

2. 1. Coiled Wire and Spiral Spring Yu et al. [16, 17] studied the developed on-line automatic rotating helical spring device in China, which is shown in Figure 1. The results show that the device not can only implement on-line continuous and automatic descaling and anti-scale function, but also can improve the tube side heat transfer coefficient by more than $30 \%$ through experimental work; the minimum speed of tube fluid flow is generally in $0.5-0.7 \mathrm{~m} / \mathrm{s}$. The inserts could rotate when the speed of tube fluid flow reaches the minimum value. The convective heat transfer correlations of tube with self-rotating helical spring inserted have been concluded as:

$$
N u=0.0119 \operatorname{Re}^{0.835} \operatorname{Pr}^{1 / 3}\left(\frac{\mu}{\mu_{w}}\right)^{0.14}
$$

where $\mu$ is the viscosity of cold fluid and $d_{\mu_{w}}$ the viscosity at the wall temperature of the water.

In order to solve the weakness of self-rotating driving force and deficiency on the capacity of resisting high temperature of plastic twisted strip, Yu et al. [18] carried out a study of the heat transfer and pressure drop characteristics of turbulent flow by using plastic coated spiral instead of traditional steel wire spiral. The results indicate that the descaling efficiency decreases slightly, but the convection heat transfer augmentation rate reaches 51.6\%. Furthermore, Xing et al. [19] experimentally studied the heat transfer, flow resistance and rotating characteristics of the different helix rotors in circular tube; the helix rotors are shown in Figure 1. The results show that heat transfer is improved by $30 \%$ and the friction factor is increased 5 times compared to those of in plain tube. The double helix rotors could continuously operate for more than half a year without any problem. The rotating speeds of the upstream rotors are higher than that of the downstream ones, while the size of single helix rotors is much smaller than the double helix.

Besides experimental investigations, numerical studies were also carried out on heat transfer enhancement technologies. Solano et al. [20] built up a computational fluid dynamics (CFD) model to investigate the effect of helical wire on the enhancement in heat transfer in pipe. The results show that laminar eddies grow downstream of the wire and spread along the next helical pitch, promoting radial mixing.

2. 2. Twisted Tape Twisted tapes are usually made of aluminum or polymer plastic with some suitable techniques. The heat transfer enhancement using twisted tapes mainly depends on the twist ratios and pitches. The twist ratio is usually defined as $y=H / d$, where $H$ is the twist pitch length and $d$ the inside diameter of the tube. Pitch is defined as the distance between two points measured parallel to the axis of the same twisted tape [21]. The sketch map of twisted tape device is shown in Figure 3. The twisted tape which is fixed on both ends of heat exchanger tube using the rotating device can rotate around the center by itself while the fluid in the tube flows.

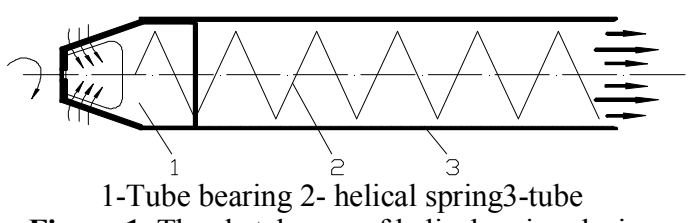

Figure 1. The sketch map of helical spring device

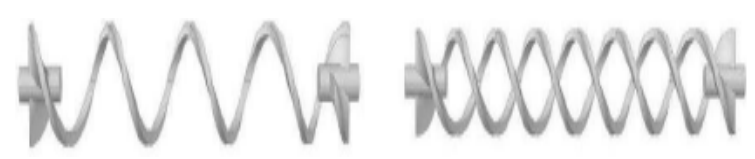

(a) the single helix rotor

(b) the double helix rotor

Figure 2. The sketch map of the helix rotor

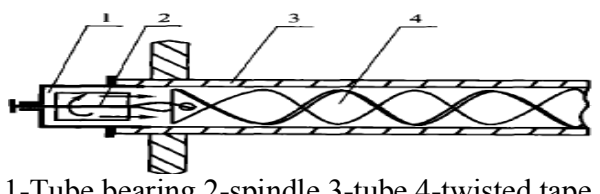

Figure 3. The sketch map of twisted tape device 


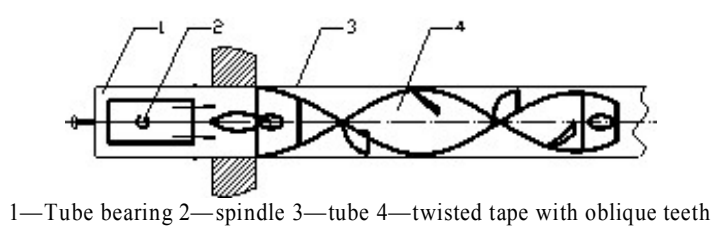

Figure 4. The sketch map of oblique teeth twisted tapedevice

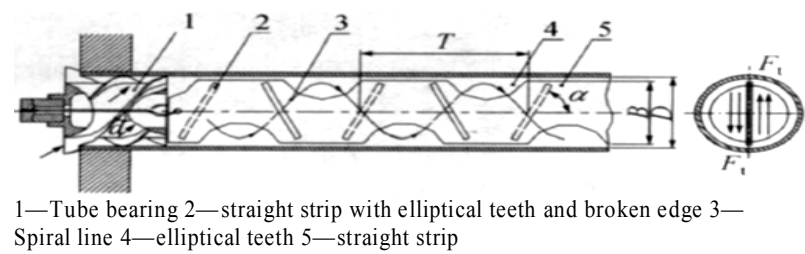

Figure 5. The sketch map of straight strip with elliptical teeth and broken edge (serrated edges) device

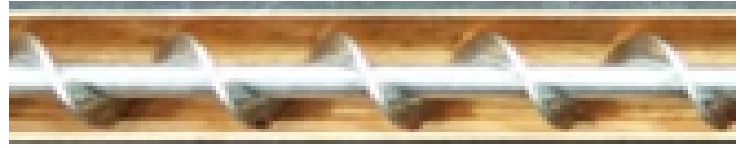

Figure 6. The sketch map of miniature hydraulic turbinedevice

Substantial number of experimental works have been carried out to study the comprehensive performance of various twisted tapes in China. Lin et al. [22] studied the heat transfer enhancement mechanisms of heat exchanger tubes with self-rotating twisted tape inserts. The results indicate that for the heat transfer enhancement, the velocity increase effect near the tube wall area and the reduction effect of the equivalent diameter are the main factors, when $y \geq 10$, the helical flow effect is the main element when $y<10$, and only when $y \leq 1$, the secondary recirculation becomes the main factor. Meanwhile, Lin et al. [23] experimentally investigated the self-preventing fouling technology for the self-rotating twisted tape in heat exchangers. Their results show that the average adhesive velocity of fouling in twisted tape tubes is only $54 \%$ of that in the plain tubes and the average dynamic thermal resistance of fouling is $30 \%$ smaller than that of the plain tubes.

$\mathrm{Yu}$ et al. [24] investigated the fouling removing and heat transfer performance at low flowing velocity by inserting twisted strip with oblique teeth into a tube, as shown in Figure 4. The principle is that there are asymmetrical oblique teeth distributed evenly on both surfaces of the strip and the heat transfer flowing fluid led by the strip has a asymmetrical reacting force on the strip over which the force moment of self-rotation is formed. The results show that this could be used to remove fouling and enhance heat transfer rate with a low flow velocity of $0.5-1.0 \mathrm{~m} / \mathrm{s}$ automatically. Comparing with the smooth twisted strip, the total moment was increased by $75-101 \%$ and the heat transfer coefficient raised by $171 \%$. Peng et al. [25] experimentally investigated the removing fouling and heat transfer enhancement characteristics of straight strip-insert with elliptical teeth and broken edges (serrated edges); this is shown in Figure 5. The spiral flow channels were designed in each elliptical gear backward position. The results indicate that comparing with twisted tape, straight strip-insert could work at the flow speed of $0.5 \mathrm{~m} / \mathrm{s}$ in tube and make the heat transfer coefficient inside tubes increase by $171 \%$. The flowing resistance equaled $3.25 \mathrm{kPa} / \mathrm{m}$ when the flow velocity in tube was $0.625 \mathrm{~m} / \mathrm{s}$.

Researchers have carried out considerable bulk of research on twisted tapes $[26,27]$. They have found that while it is obvious that the twisted tapes can improve the heat transfer rate, the performance of twisted tape inserts is better with laminar flow. It could reduce the extra pressure drop by using short length twisted tapes or multiple short length twisted tapes.

\section{3. Miniature Hydraulic Turbine}

The technology of online anti-scaling and descaling in the heat exchanger using miniature hydraulic turbine was proposed by Lin et al. [28]. This device is shown in Figure 6. Miniature hydraulic turbines are made by welding a blade on a tube. In order to be easily placed in the heat exchanger tube, its diameter is smaller than the inside diameter of heat exchanger tube. The convective heat transfer correlations of tube with miniature hydraulic turbine inserted have been concluded as:

$N u=0.0119 \operatorname{Re}^{0.835} \operatorname{Pr}^{1 / 3}\left(\frac{\mu}{\mu_{w}}\right)^{0.14}$

where $\eta$ is the viscosity of cold fluid and $\eta_{\mathrm{w}}$ the viscosity of the wall temperature of the water.

Considerable of experimental work and theoretical researcher as been conducted by Lin et al. [29-31] to study the performance of various miniature hydraulic turbines. All the results indicate that the heat transfer rate is enhanced significantly, while the pressure loss raises only slightly with the miniature hydraulic turbine. In contrast with a plain tube, the miniature hydraulic turbine can enhance heat transfer to some extent. The rotating speed is $850 \mathrm{rpm}$ when the flow velocity in tube is $1 \mathrm{~m} / \mathrm{s}$. The heat transfer $\mathrm{Nu}$ number and friction resistance increases 1.49-1.62 and 1.13-1.16 times respectively compared with those in a plain non-fouling tube. It is found that the average dynamic fouling with miniature hydraulic turbine is $30 \%$ smaller than that of the smooth tubes by online industrial test.

2. 4.Helical Blade Rotor Helical blade rotors shown in Figure 7 are a new addition to the family of inserts for descaling and heat transfer enhancement [32]. Meanwhile, helical blade rotors have a wide range of 
applications in a variety of engineering areas. Yang et al. [33] experimentally investigated the heat transfer and single phase pressure drop with rotor-assembled strands inserted tubes with the Reynolds number ranging from 2300 to 9000 . The results show that the $\mathrm{Nu}$ number is increased by 30 to $60 \%$. Helical blade rotors could work at the flow speed of $0.2 \mathrm{~m} / \mathrm{s}$ in tube; the rotating speed of the Helical blade rotors reach $600 \mathrm{rpm}$ when the fluid velocity is $1 \mathrm{~m} / \mathrm{s}$.

The convective heat transfer correlations of tube with helical blade rotor inserted have been concluded as follows:

$$
\mathrm{Nu}=0.023 \operatorname{Re}^{0.8} \operatorname{Pr}^{0.4} i_{1}^{-0.2}\left(i_{2} i_{3} i_{4}\right)^{0.8}
$$

where $i$ is scale factor of the tube axial average flow velocity of the fluid in smooth tube.

Zhang et al. [34] experimentally studied the effects of rotor assembly with helical lobes and grooved helical lobes on the characteristics of flow friction and thermal performance in a circular tube. The results indicate that the $\mathrm{Nu}$ number with helical lobe rotor assembly and grooved helical lobe rotor assembly increased 1.06-1.26 and 1.03-1.15 times of that of the plain tube, respectively. The friction factor with helical lobe rotor assembly and grooved helical lobe rotor assembly increased $60-68 \%$ and $36-51 \%$ with respect to that of the plain tube, respectively. Grooved helical lobe rotor assembly has a better thermal performance characteristic. Except the research wok of Zhang et al. [33], most of research works mentioned the swirl flow devices which are the fixed type swirl inserts.

Duangthongsuk et al. [35, 36] experimentally investigated the heat transfer and pressure drop characteristics of a circular tube fitted with rotating and fixed turbine-type swirl generator; this is shown in Figure 8. The data for a common smooth tube is compared with the data for fixed (FTSG) and freely rotating turbine type swirl generator (RTSG). The measured data illustrates that the heat transfer performance of the tube with RTSG inserts is 6.3 and $56 \%$ higher than that of the FTSG insert and the conventional smooth tube, respectively. The pressure drops of the tube with RTSG inserted were higher than those of the conventional plain tube by approximately 2.5 times. Compared with the FTSG inserts, the tube with RTSG inserts gives the lowest pressure drop.

2. 5. Imbalance Spiral-gear The imbalance spiralgear inserts which are shown in Figure 9, are proposed to solve online fouling removal problem in heat transfer tubes. Peng et al. [37] experimentally studied the selfrotating and convective heat transfer performance of imbalance spiral-gear inserts. The results show that the imbalance spiral-gear connected clockwise and counterclockwise alternately can spin more easily, and the imbalance spiral-gear could rotate when the fluid flow velocity is $0.35 \mathrm{~m} / \mathrm{s}$. When the heat transfer temperature difference is 15 , the overall heat transfer coefficient of the imbalance spiral-gear tube is 89 to $112 \%$ greater than that of straight plain tube, and 12 to $25 \%$ higher than that with balanced spiral-gear insert. The spiral-gears connected clockwise and counterclockwise alternately have the greatest force moment and can spin more easily.

2. 6. New Rotor New rotor inserts were proposed based on the helix rotor structures that already existed to further reduce the flow resistance, which is shown in Figure 10. Xin et al. [19, 38, 39] numerically and experimentally investigated the flow resistance, antifouling features and rotor rotation characteristics in a circular tube fitted with new rotor inserts. The results show that the rotating speed of the new rotor reaches $100 \mathrm{rpm}$ when fluid flow velocity is $0.76 \mathrm{~m} / \mathrm{s}$, the flow resistance of circular tube with the new rotor insert has a2 times increase compared with that of the plain tube. The flow resistance could be further reduced to 1.4 times increase by adding diversion frustum and smaller radius of the rotational sleeve. The weight of the plain tube increases $1.6 \mathrm{~g}$ compared to that fitted with new rotor inserts after 10 days of continuous operation. Appropriately increasing the helix pitch of rotor, reducing the gap between blade and tube wall and reducing the radius of rotating shaft can lead to a better heat transfer performance.

Based on the MRF model and the moment balance method, Zhu et al. [40] used CFD simulation to study the fluid flow in circular tubes inserted with blade helical rotors and straight-line rotors. The results indicate that the flow resistance of the circular tube with straight-line rotors inserted is 3 to 4 times of that of the plain tube, half of the circular tube inserted with blade helical rotors.

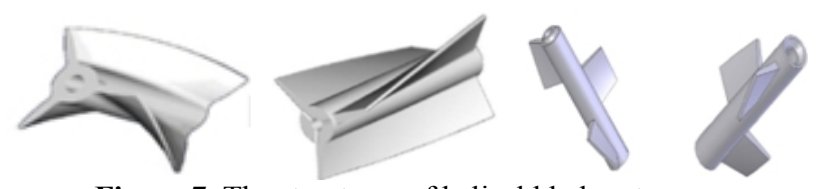

Figure 7. The structures of helical blade rotors

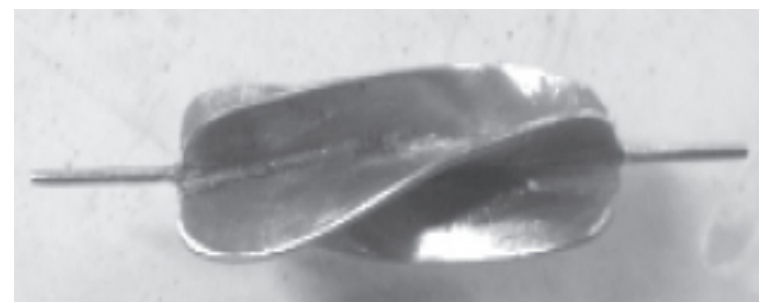

Figure 8.Bare FTSG and RTSG 


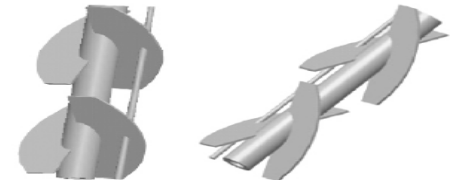

Figure 9. The sketch map of imbalance spiral-gear

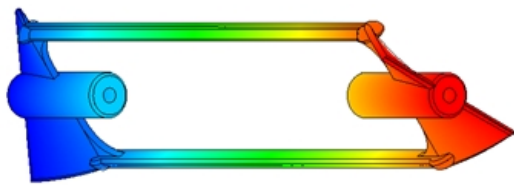

Figure 10.The sketch map of new rotor

TABLE 1. The Performance Comparisons of Self-rotating Inserts

\begin{tabular}{|c|c|c|c|}
\hline Self-rotating Inserts & Characteristics of Rotating & $\begin{array}{c}\text { Heat Transfer } \\
\text { Enhancement }(\%)\end{array}$ & $\begin{array}{c}\text { Resistance } \\
\text { Increment(times) }\end{array}$ \\
\hline $\begin{array}{l}\text { Coiled Wire and Spiral } \\
\text { Spring }[16-20]\end{array}$ & The minimum speed of tube fluid flow is generally in $0.5 \mathrm{~m} / \mathrm{s}$ & $4.67-87.14$ & $0.52-3.46$ \\
\hline Twisted Tape[21-25] & The minimum speed of tube fluid flow is generally in $0.3 \mathrm{~m} / \mathrm{s}$ & $32-171$ & $1.57-5.08$ \\
\hline $\begin{array}{l}\text { Miniature Hydraulic } \\
\text { Turbine[28-31] }\end{array}$ & $\begin{array}{l}\text { The rotating speed was } 850 \mathrm{r} / \mathrm{min} \text { when the flow velocity in } \\
\text { tube was } 1 \mathrm{~m} / \mathrm{s}\end{array}$ & & $4-5$ \\
\hline Helical Blade Rotor[32-34] & $\begin{array}{l}\text { The rotating speed was } 600 \mathrm{r} / \mathrm{min} \text { when the flow velocity in } \\
\text { tube was } 1 \mathrm{~m} / \mathrm{s}\end{array}$ & & $3-5$ \\
\hline New Rotor[19, 38-40] & $\begin{array}{l}\text { The rotating speed was } 100 \mathrm{r} / \mathrm{min} \text { when the flow velocity in } \\
\text { tube was } 0.76 \mathrm{~m} / \mathrm{s}\end{array}$ & & $4-5$ \\
\hline Imbalance Spiral-gear[37] & The minimum speed of tube fluid flow is generally in $0.35 \mathrm{~m} / \mathrm{s}$ & $89-112$ & 4.4-8.69 \\
\hline
\end{tabular}

\section{THE PERFORMACE COMPARISONS OF SELF- ROTATING INSERTS}

The various performance comparisons of self-rotating inserts are shown in Table 1. All the performances of tube with a self-rotating insert are compared with those of a plain tube without inserts. It can be concluded that both the heat transfer rate and the pressure drop increased with the tube fitted with self-rotating inserts. The development trend of self-rotating inserts is with a smaller and streamline configuration in overall dimensions in order to reduce the resistance loss.

\section{CONCLUSION}

Self-rotating inserted into a conventional smooth tube is an innovative way to increase the thermal performance of the heat exchangers. The numerical simulations and experimental studies have been conducted to investigate the characteristics of heat transfer rate and friction factor of the tube fitted with self-rotating inserts. The conclusions are listed as follows:

1. Compared with the stationary inserts, both the heat transfer enhancement and the function of on-line automatic self-cleaning can be achieved with the selfrotating inserts in tube. Meanwhile, the non-fouling equipment can be operated efficiently with the selfrotating inserts in tube.

2. Most of the researchers need to decrease the extra pressure loss by using self-rotating inserts. In the selection of the self-rotating inserts, the structure of the insert is the major parameter. When the fluid velocity is more than $0.2 \mathrm{~m} / \mathrm{s}$, most of self-rotating inserts can be applied, meanwhile the convective heat transfer correlations have been discussed.

3. The heat transfer coefficient significantly increases when the fluid flows past the stationary and self-rotating inserts. However, the stationary and selfrotating inserted into the common smooth tube results in an increase of the pressure drop. The tube with selfrotating inserts gives the lowest pressure drop.

4. Along with the increase of the heat transfer rate, the pressure drop increases significantly in tube with the self-rotating inserts. The best performance of the optimal self-rotating inserts inserted in a tube has the topmost heat transfer rate and the lowest resistance loss. Determining how to find the optimal parameter is the main objective of the study for researchers.

\section{REFERENCES}

1. Liebenberg, L. and Meyer, J.P., "In-tube passive heat transfer enhancement in the process industry", Applied Thermal Engineering, Vol. 27, No. 16, (2007), 2713-2726.

2. Sheikhzadeh, G., Arefmanesh, A., Kheirkhah, M. and Abdollahi, R., "Numerical study of natural convection in an inclined cavity with partially active side walls filled with cu-water nanofluid", International Journal of Engineering-Transactions B: Applications, Vol. 24, No. 3, (2011), 279-288

3. Jahanshahi Javaran, E., Gandjalikhan Nassab, S. and Jafari, S., "Numerical simulation of a three-layered radiant porous heat exchanger including lattice boltzmann simulation of fluid flow", International Journal of Engineering. Transactions A: Basics; Vol. 24, No. 3, (2011), 301-319.

4. Rostamzadeh, A., Jafarpur, K., Goshtasbirad, E. and Doroodmand, M., "Experimental investigation of mixed convection heat transfer in vertical tubes by nanofluid: Effects of reynolds number and fluid temperature", International Journal 
of Engineering-Transactions B: Applications, Vol. 27, No. 8, (2014), 1251-1260

5. Goudarzi, K., Yousef-abad, S.A., Shojaeizadeh, E. and Hajipour, A., "Experimental investigation of thermal performance in an advanced solar collector with spiral tube", International Journal of Engineering-Transactions A: Basics, Vol. 27, No. 7, (2013), 1149

6. Bas, H. and Ozceyhan, V., "Heat transfer enhancement in a tube with twisted tape inserts placed separately from the tube wall", Experimental Thermal and Fluid Science, Vol. 41, No.3, (2012), 51-58.

7. Wongcharee, K. and Eiamsa-Ard, S., "Friction and heat transfer characteristics of laminar swirl flow through the round tubes inserted with alternate clockwise and counter-clockwise twistedtapes", International Communications in Heat and Mass Transfer, Vol. 38, No. 3, (2011), 348-352.

8. Moawed, M., "Heat transfer and friction factor inside elliptic tubes fitted with helical screw-tape inserts", Journal of Renewable Sustainable Energy, Vol. 3, (2011), 1-15.

9. Guo, J., Fan, A., Zhang, X. and Liu, W., "A numerical study on heat transfer and friction factor characteristics of laminar flow in a circular tube fitted with center-cleared twisted tape", International Journal of Thermal Sciences, Vol. 50, No. 7, (2011), 1263-1270.

10. Shabanian, S., Rahimi, M., Shahhosseini, M. and Alsairafi, A., "Cfd and experimental studies on heat transfer enhancement in an air cooler equipped with different tube inserts", International Communications in Heat and Mass Transfer, Vol. 38, No. 3, (2011), 383-390.

11. Anvari, A., Lotfi, R., Rashidi, A. and Sattari, S., "Experimental research on heat transfer of water in tubes with conical ring inserts in transient regime", International Communications in Heat and Mass Transfer, Vol. 38, No. 5, (2011), 668-671.

12. Promvonge, P., Khanoknaiyakarn, C., Kwankaomeng, S. and Thianpong, C., "Thermal behavior in solar air heater channel fitted with combined rib and delta-winglet", International Communications in Heat and Mass Transfer, Vol. 38, No. 6 , (2011), 749-756.

13. Tuo, H., "Thermal-economic analysis of a transcritical rankine power cycle with reheat enhancement for a low-grade heat source", International Journal of Energy Research, Vol. 37, No. 8, (2013), 857-867.

14. Tuo, H. and Hrnjak, P., "New approach to improve performance by venting periodic reverse vapor flow in microchannel evaporator", International Journal of Refrigeration, Vol. 36, No. 8, (2013), 2187-2195.

15. Liu, S. and Sakr, M., "A comprehensive review on passive heat transfer enhancements in pipe exchangers", Renewable and Sustainable Energy Reviews, Vol. 19, No., (2013), 64-81.

16. Yu, X.M. and and Yu, T.L., "The experimental study of automatic rotating helical heat transfer technology", Chemical Equipment Technology, Vol. 18, (1997), 4-8.

17. Yu, X.M., Wu, J.X. and and Yu, T.L., "The rotating and vibrating spiral of cleaning and preventing fouling automaticity", Chemical Cleaning, Vol. 12, (1996), 34-37.

18. Yu, T., Liu, G., Yu, X. and ZHI, X.-h., "Automatic cleaning and heat transfer enhancing technology for intensified steel spiral with plastic coat on driving wheel", Journal of Engineering Design. Hangzhou, Vol. 13, No. 2, (2006), 95-98.

19. Xing, C., Meng, J.A. and and Li, Z.X., "Heat transfer and rotating features of inserted spring rotors", Journal of Engineering Thermophysics, Vol. 31, (2010), 2105-2108.

20. Solano, J., Herrero, R., Espín, S., Phan, A. and Harvey, A., "Numerical study of the flow pattern and heat transfer enhancement in oscillatory baffled reactors with helical coil inserts", Chemical Engineering Research and Design, Vol. 90, No. 6, (2012), 732-742.

21. Sarada, S.N., Raju, A.S.R., Radha, K.K. and Sunder, L.S., "Enhancement of heat transfer using varying width twisted tape inserts", International Journal of Engineering, Science and Technology, Vol. 2, No. 6, (2010).

22. Lin, Z. and Qian, H.W., Yu, X.M., and Yu, X.M.,, "Heat transfer enhancement mechanims of heat exchanger tubes with rotating twisted tape insert", Chinese Journal of Mechanical Engineering, Vol. 43, (2007), 140-143.

23. Lin, Z., You, Y.K., Qian, H.W., Liu, Y., Yu, X.M., and and Yu, X.M., "Experimental research of self-preventing fouling technology for the self-rotating twisted tape in heat exchangers", Chemical Engineering, Vol. 34, (2006), 16-19.

24. Yu, T., Yu, X., Zhi, X., JIANG, S. and PENG, D., "Research on the twisted strip with teeth to enhance self-cleaning ability of heat transfer tubes at low flowing velocity", Natural Science Journal-Xiangtan University, Vol. 26, No. 1, (2004), 89-91.

25. Peng, D.Q., Liang, G.Y., Yu, X.M., and and Jin, J.J., "New straight strip-insert with elliptical teeth and broken edge for removing fouling and enhancing heat transfer", Journal of Engineering Design, Vol. 13, No. 6, (2006), 392-395.

26. Eiamsa-Ard, S., Thianpong, C., Eiamsa-Ard, P. and Promvonge, P., "Thermal characteristics in a heat exchanger tube fitted with dual twisted tape elements in tandem", International Communications in Heat and Mass Transfer, Vol. 37, No. 1, (2010), 39-46.

27. Ibrahim, E., "Augmentation of laminar flow and heat transfer in flat tubes by means of helical screw-tape inserts", Energy Conversion and Management, Vol. 52, No. 1, (2011), 250-257.

28. Lin, R., Lin, Q., Feng, Q. and Shi, W., "Study on the miniature hydraulic turbine in the heat exchanger tube", Jixie Gongcheng Xuebao(Chinese Journal of Mechanical Engineering)(China), Vol. 37, No. 7, (2001), 41-43.

29. Lin, J.Y., Lin, Q.Y. and and Lin, R.D., "Rotating speed calculation for hydraulic turbine inside heat exchanger tubes", Chinese Journal of Mechanical Engineering, Vol. 44, (2008), 105-111.

30. Lin, Q.Y., Lin, R.D. and and Li, P.N., "Experimental on the primary structural parameters of self-antifouling hydraulic turbine inside heat exchanger tube", Chinese Journal of Mechanical Engineering, Vol. 15, (2004), 346-348.

31. Li, Q.Y., Li, P.N. and and Lin, R.D., "Study on the heat transfer enhancement by the hydraulic turbine in a tube", Chinese Journal of Mechanical Engineering, Vol. 40, (2004), 165-169.

32. Yang, W., Ding, Y., Geng, L. and Huang, W., "Rotor-assembled automatic cleaning and heat transfer enhancement device", $\boldsymbol{C N}$ Pat., (2005)

33. Zhang, Z., Yang, W., Guan, C., Ding, Y., Li, F. and Yan, H., "Heat transfer and friction characteristics of turbulent flow through plain tube inserted with rotor-assembled strands", Experimental Thermal and Fluid Science, Vol. 38, (2012), 3339.

34. Zhang, Z., Yan, H., Yang, W., Zhou, Y., Ding, Y. and Guan, C., "Heat transfer enhancement in the tube fitted with left-right helical blade rotors", Applied Thermal Engineering, Vol. 55, No. 1, (2013), 95-101.

35. Duangthongsuk, W. and Wongwises, S., "An experimental investigation of the heat transfer and pressure drop characteristics of a circular tube fitted with rotating turbine-type swirl generators", Experimental Thermal and Fluid Science, Vol. 45, No., (2013), 8-15

36. Duangthongsuk, W. and Wongwises, S., "Comparison of the heat transfer performance and friction characteristics between fixed and rotating turbine-type swirl generators fitted in a small 
circular tube", Experimental Thermal and Fluid Science, Vol. 50, (2013), 222-228.

37. Peng, D.Q., Tian, Q., Yu, T.L., , Wang, W.Q., Wang, Z.Q. and and Luo, G., "Self-rotating and convective heat transfer performance of imbalance spiral-gear insert in tubes", CIESC Journal, Vol. 64, (2013), 2833-2838.

38. Xing, C., Meng, J.A. and and Li, Z.X., "Flow resistance and anti-fouling features of inserted auto-rotating rotors", Journal of Engineering Thermophysics, Vol. 32, (2011), 655-658.
39. Xing, C., MENG, J.a. and LI, Z., "Flow resistance and rotor rotation characteristics in a circular tube with new rotor inserts", Journal of Tsinghua University (Science and Technology), Vol. 5, (2011), 031-40.

40. Zhu, X.L., Meng, J.A. and and Li, Z.X., "Numerical simulation and analysis of flow in circular tube with rotors insert", Journal of Engineering Thermophysics, Vol. 34, (2013), 1123-1126. 


\title{
Review Heat Exchanger: Research Development of Self-rotating Inserts in Heat Exchanger Tubes
}

\author{
Z. Cancan, L. Yafei, W. Li, X. Ke, W. Jinxing
}

School of Chemical and Energy Engineering, Zheng Zhou University,Zheng Zhou ,China

PAPER INFO

Paper history:

Received 18 January 2014

Received in revised form 17 May 2014

Accepted 26 June 2014

\section{Keywords:}

TubeInserts

Self-rotating

Heat Transfer Enhancement

Anti-scaling and Descaling
مبدل هاى حرارتى به طور گسترداى در توليد انرزى و كاربردهاى صنعتى استفاده مىشود. فنون متعددى مانند لولههاى

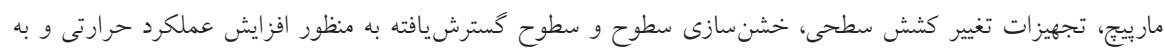

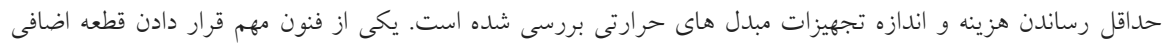

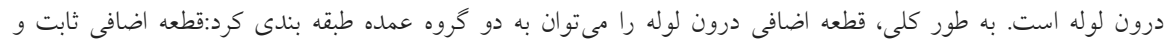

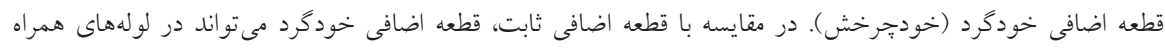

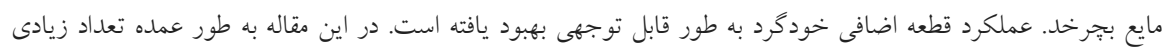

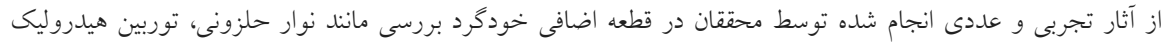

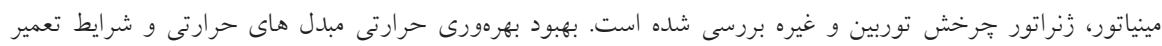

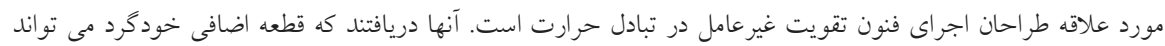

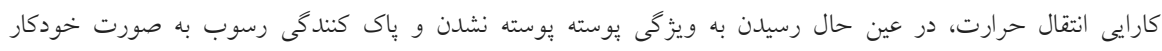

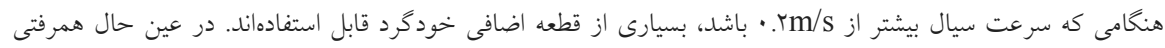

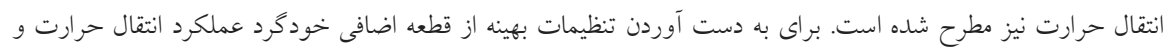

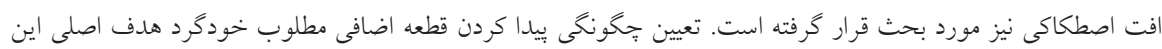




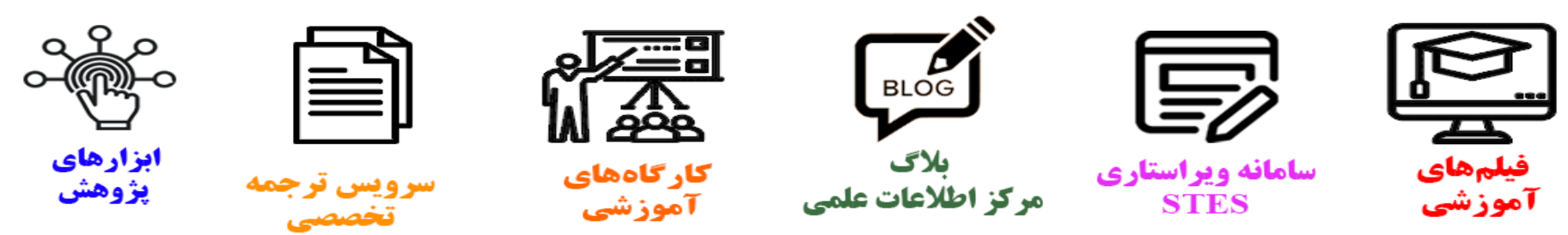

\section{(c)}

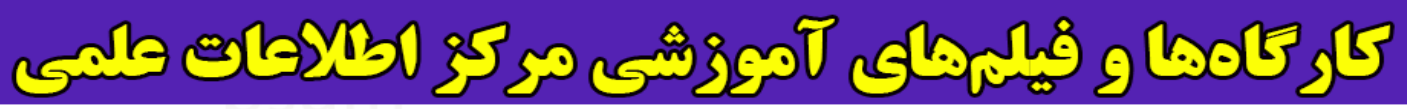
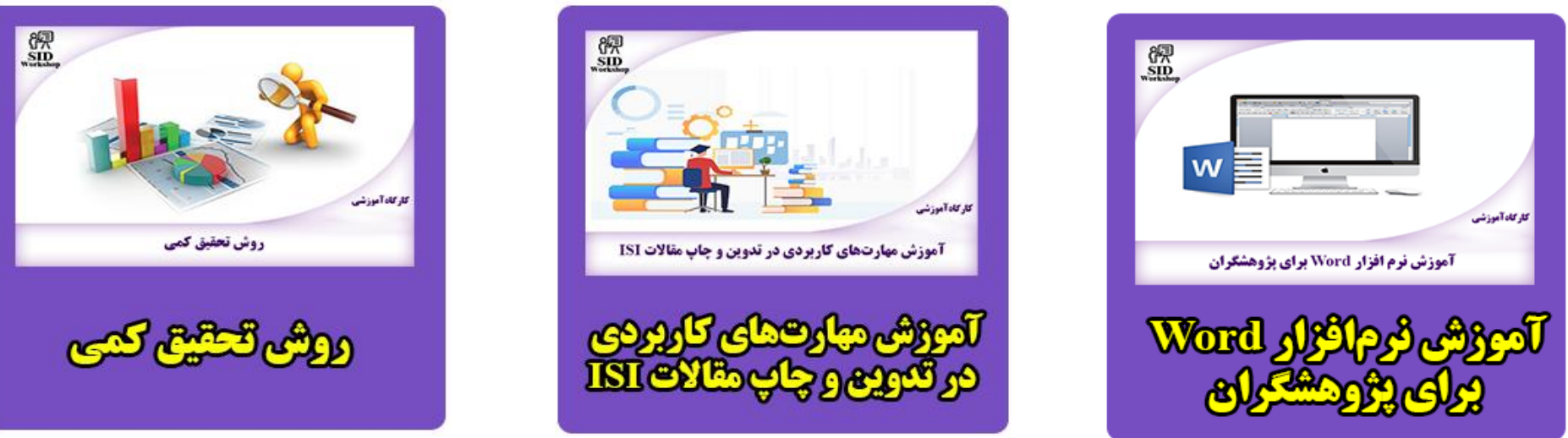